sections are admirably critical, others are mere compilations of quite elementary facts and ideas.

The best sections are undoubtedly the most critical. Chapters iv (spectrometric instruments and their adjustment), vi (radiometry), x (galvanometers), xii (pyrometry) appear to me admirable ; if the other chapters had shown equal knowledge and insight, the book, though it would have been a mere set of essays on slightly related subjects, might have been of great value. Chapter viii (photographic measurement) approaches the encyclopædic ideal, but is open to the objection that other works of greater length discuss the same matter with equal skill and in necessarily greater detail. Chapter i (fundamental ideas) might have been abbreviated to a simple list of formulæ; on the other hand, not even Messrs. Forsythe and Ives can treat photometry (chapter xiii) adequately in 18 pages. The remaining chapters seem to me satisfactory so far as they go, but undistinguished ; it is difficult to guess to whom precisely they are addressed.

These are, however, all matters of opinion; the editor's and authors' names are a sufficient guarantee that there will be no serious errors; I can only hope that others will find in this work a higher value than $I$ have been able to put upon it.

Norman R. Campbell.

\title{
Nutrition and Dietetics
}

(I) The Little Things in Life :

the Vitamins, Hormones and other Minute Essentials for Health. By Prof. Barnett Sure. Pp. xii + 340. (New York and London: D. AppletonCentury Co., Inc., 1937.) $8 s .6 d$. net.

(2) Elements of Foods and Nutrition

By Mary T. Dowd and Prof. Alberta Dent. Pp. xiii +279 . (New York: John Wiley and Sons, Inc.; London: Chapman and Hall, Ltd., 1937.) $8 s$. $6 d$. net.

(3) Dietetics Simplified :

the Use of Foods in Health and Disease. By Prof. L. Jean Bogert. With Laboratory Section by Mame T. Porter. Pp. ix +637 . (New York: The Macmillan Co., 1937.) 12s. 6d. net.

7 HIS series of American books dealing with 1 nutrition illustrates some of the methods by which the results of scientific inquiry may be made generally available for the benefit of a community.

(1) The method adopted by Prof. Sure is to present the more dramatic aspects of the subject in a form which may appeal to the intelligent layman. In "The Little Things of Life" he describes the part played by vitamins, mineral elements and hormones in the regulation of living processes, his main theme being the influence of these chemical substances on nutrition and therefore on health. Though written in "non-technical language", the account he gives is more detailed than might be expected from the title. Laymen introduced for the first time to the new knowledge of nutrition might digest more easily a plainer story, in which less attention is given to the chronological sequence of individual discoveries. The general public is usually content with getting some grasp of the main significance of scientific discoveries and is not deeply interested in settling questions of priority.
Nevertheless, the persistent reader will obtain much interesting information from this volume, and he should be duly impressed with the way in which recent biochemical work is being applied to the prevention and treatment of human disease.

(2) The little book by Dowd and Dent is avowedly a text-book for use in schools, and fulfils well its purpose of providing a basis for the teaching of good food habits to children in their more advanced forms. The subjects dealt with include not only the physical and chemical properties of the individual components of food and their function in nutrition, but also the principles of food selection for the purpose of securing good nutrition, with due regard to the cost of living. A useful chapter is added on common food fallacies, in which the fantastic views of certain types of food faddist are exposed. Numerous illustrations are included.

(3) The last of these books, "Dietetics Simplified," is again a text-book, but with an appeal to a more specialized audience-students of domestic science, hospital dietitians, nurses, medical students and perhaps intelligent housewives. The first two sections contain a clear and practical exposition of the principles of nutrition as applied to the normal human being. These are followed by a section devoted to the use of diet as a therapeutic agent in disease. It is shown how the normal good diet may be modified to suit the particular requirements of the subjects of disease. The reasons for advising the suggested modifications are given and these are in accord with current medical and scientific thought. The last third of the book is a practical manual of menu-planning and cookery. All those whose work includes the planning of diets for promoting health and treating established disease will find in this volume a mine of valuable information. 